\title{
Relato de Experiência Vivenciada no PIBID sobre a Utilização da Computação Desplugada, a Hora do Código e do Scratch no Ensino Médio
}

\author{
Anna Raquel da S. Marinho' ${ }^{1}$ Pauleany S. de Morais ${ }^{2}$, Givanaldo R. de Souza ${ }^{3}$, \\ Alba S. L. do Nascimento ${ }^{1}$ \\ ${ }^{1}$ Campus Zona Norte - Instituto Federal do Rio Grande do Norte (IFRN) \\ Natal - Rio Grande do Norte - Brasil \\ ${ }^{2}$ Campus de Educação a Distância - Instituto Federal do Rio Grande do Norte (IFRN) \\ Natal - Rio Grande do Norte - Brasil \\ ${ }^{3}$ Campus Parnamirim - Instituto Federal do Rio Grande do Norte (IFRN) \\ Parnamirim - Rio Grande do Norte - Brasil \\ raquelmarinho.linfor@gmail.com, pauleany.morais, givanaldo.rocha, \\ alba.lopes\} difrn.edu.br
}

\begin{abstract}
This article aims to present an application of Science Unplugged, the Hour of Code and Scratch as tools for introducing Computational Thinking in High School. The methodology used in the development of this work is based on action-research (LEWIN, 1946). The experiences lived in Institutional Scholarship Program Introduction to Teaching (PIBID), Informatics subproject. After analyzing the results achieved, it is considered that it is possible to introduce the concept of Computational Thinking in High School, in order to allow students to be actors in the teaching and learning process.

Resumo. Este artigo objetiva apresentar a utilização da Computação Desplugada, a Hora do Código e o Scratch como ferramentas de introdução ao Pensamento Computacional no Ensino Médio. A metodologia utilizada no desenvolvimento deste trabalho é baseada na pesquisa-ação (LEWIN, 1946). A experiência relatada foi vivenciada nas ações do Programa Institucional de Bolsas de Iniciação à Docência (PIBID), subprojeto Informática. Ao analisar os resultados alcançados, considera-se que é possivel introduzir o conceito de Pensamento Computacional no Ensino Médio, tendo em vista permitir que os alunos sejam atores no processo de ensino e aprendizagem.
\end{abstract}

\section{Introdução}

Sabe-se que "é importante que juntamente com a inserção do computador na vida dos alunos, o método de ensinar e o conteúdo ensinado sofram alterações que permitam o uso efetivo e qualitativo dessa ferramenta tecnológica" (SILVA; ROMANI; BARANAUSKAS, 2008, p.31). Sendo assim, este trabalho apresenta em suas seções algumas considerações sobre perspectivas para o ensino de Informática, por meio da utilização da Computação Desplugada, a Hora do Código e do Scratch.

A experiência aqui relatada é baseada no método da pesquisa-ação (LEWIN, 1946), cujo processo orienta o pesquisador a seguir as etapas de identificar as estratégias de ação a serem implementadas, sistematizar a observação, reflexão e mudança 
(GRUNDY; KEMMIS, 1982). Nessas etapas, de acordo com Tripp (2005, p. 446) "planeja-se, implementa-se, descreve-se e avalia-se uma mudança para a melhora de sua prática, aprendendo mais, no correr do processo, tanto a respeito da prática quanto da própria investigação".

Trata-se de uma abordagem experimental, visto que as estratégias utilizadas perpassam a metodologia de ensino tradicional ao construtivismo com o objetivo de atender à aprendizagem cognitivista, na qual o sujeito deve utilizar habilidades de raciocínio lógico para resolver os problemas propostos. Portanto, sugere-se que as técnicas utilizadas nas ações de pesquisa e investigação devam ser tomadas com fins de melhorar prática (TRIPP, 2005).

A primeira parte desse estudo ocorreu no ano de 2015, cuja experiência é relatada em Marinho et. al. (2017). A partir da análise das metodologias utilizadas, das respostas dos questionários aplicados e dos resultados alcançados na $1^{\mathrm{a}}$ experiência, foi realizado um segundo estudo que corroborou com a concepção das estratégias utilizadas na $2^{\mathrm{a}}$ experiência (no ano de 2016), que será relatada neste trabalho. Na Seção 2 serão apresentadas as ferramentas e a técnica utilizadas. Na Seção 3, as Experiências de Introdução ao Pensamento Computacional no Ensino Médio. Por fim, na Seção 4, as considerações finais.

\section{O Pensamento Computacional e as ferramentas utilizadas}

Desde o primeiro artigo da Jeannette Wing, publicado em 2006, dissertando sobre o Pensamento Computacional, os pesquisadores de Informática na Educação têm utilizado estratégias que corroboram com a operacionalização de práticas pedagógicas que mobilizam competências do pensar computacionalmente.

Pensamento Computacional é uma forma para seres humanos resolverem
problemas; não é tentar fazer com que os seres humanos pensem como
computadores [...]; humanos são espertos e imaginativos. Nós humanos
tornamos a computação empolgante. Equipados com aparelhos
computacionais, usamos nossa inteligência para resolver problemas que não
ousaríamos sequer tentar antes da era da computação e construir sistemas
com funcionalidades limitadas apenas pela nossa imaginação (WING, 2006,
p. 4).

Ou seja, o pensar computacionalmente não é restrito apenas a quem está inserido na área da computação, mas apresenta-se como uma competência que, de acordo com Cavalcante, Costa e Araújo (2016, p. 1119), "consiste em um conceito mais abrangente no qual há um conjunto de habilidades e atitudes vinculadas na realização de uma ação", relevante para todas as pessoas, considerando que um dos principais objetivos é a resolução de problemas, independente da área do conhecimento. Diante destas perspectivas, serão descritas as duas ferramentas e a técnica utilizadas durante a oficina relatada neste trabalho: a Hora do Código, o Scratch e a Computação Desplugada, respectivamente.

\subsection{A Hora do Código (The Hour of Code)}

A Hora do Código é um movimento da Code Studio (2017), criado com o intuito de demonstrar que independente da idade, gênero, etnia e do conhecimento que as pessoas possuem é possível aprender conceitos básicos de programação por meio de desafios lúdicos online. O movimento busca oportunizar experiências de utilização de 
alguns fundamentos da ciência da computação. Essas experiências contribuem para o desenvolvimento de habilidades como raciocínio lógico, resolução de problemas e criatividade.

Os desafios da Hora do Código contêm tutoriais em forma de vídeos e balões explicativos com instruções para que o usuário consiga entender sem dificuldades o funcionamento do programa e atingir o objetivo de cada fase. Não é necessário cadastrar-se para participar dos desafios. Ao completar todas as fases o sistema gera um certificado de participação que pode ser compartilhado no Facebook. O site code.org oferece outros cursos, para crianças a partir dos 4 anos de idade. Além dos desafios e cursos online, são disponibilizadas instruções de atividades desplugadas (sem o uso do computador).

\subsection{A ferramenta Scratch}

Desenvolvido para que o usuário possa programar suas próprias histórias interativas, jogos e animações e compartilhar suas criações com outros membros da comunidade online. Foi projetado especialmente para estudantes entre 8 e 16 anos, mas é usado por pessoas de todas as idades. O Scratch é usado em mais de 150 países e está disponível em mais de 40 idiomas (SCRATCH, 2015). O acesso à ferramenta pode ser feito online, porém é possível fazer o download da versão instalável. Esta versão é compatível com os sistemas operacionais Mac, Windows e algumas versões do Linux, no entanto para que o programa funcione é preciso instalar também o Adobe Air - disponibilizado na própria página de download do Scratch: https://scratch.mit.edu/.

\subsection{A Computação Desplugada}

A Computação Desplugada (do inglês, Science Unplugged), conforme Bell et al. (2011), pode ser caracterizada como um método de ensino de fundamentos da computação sem o uso do computador, a qual possibilita o ensino de conceitos computacionais de maneira lúdica, podendo ser utilizada do ensino fundamental ao ensino superior. A relevância da utilização desta técnica é evidenciada na fala de Vieira, Passos e Barreto (2013, p.672) quando destacam "a sua independência de recursos de hardware ou software" por

\footnotetext{
(i) não requerer computadores; (ii) ensino da ciência da computação real; (iii) aprender fazendo; (iv) ser divertido; (v) sem nenhum equipamento especializado; (vi) variações da aplicação da técnica são encorajadas; (vii) para qualquer pessoa; (viii) durante as atividades, enfatizar a cooperação, comunicação e solução de problemas; (ix) atividades são auto-suficientes, ou seja, podem ser usadas independentemente umas das outras e; (x) devem ser flexíveis com relação a erros, isto é, pequenos erros não devem impedir que os participantes entendam os fundamentos (Vieira, Passos e Barreto, 2013, p.672).
}

\subsection{Produção de Jogos Educacionais}

Uma alternativa bastante utilizada nos últimos anos para a introdução à programação de acordo com Gomes, Tedesco e Melo (2016, p. 62) "é o desenvolvimento de jogos digitais por meio de linguagens visuais de programação". Essa alternativa possibilita o desenvolvimento de competências do Pensamento Computacional. A produção de jogos permite trabalhar com os alunos a resolução de problemas e o raciocínio lógico, dentre outras habilidades, de maneira lúdica. 
Nessa perspectiva, Gomes, Tedesco e Melo (2016) dissertam que nas práticas introdutórias à programação recomenda-se a utilização de técnicas que possibilitem a aprendizagem por meio da prática. No entanto, ressaltam como um dos desafios a escolha das ferramentas que atendam grupos heterogêneos.

\section{Introdução ao Pensamento Computacional no Ensino Médio}

A abstração dos conhecimentos depende muito da forma em que eles são apresentados. Por consequência, não é viável simplesmente descaracterizar a importância da aprendizagem escolar em detrimento dos recursos tecnológicos informacionais. Mesmo que exista a informação e que haja um processo cognitivo aliado, se faz necessário a orientação que está presente no contexto escolar (LIBÂNEO, 2000). Cabe aos educadores orientar os seus alunos sobre como utilizar a tecnologia de forma proveitosa, para a produção do conhecimento.

As ações realizadas na Escola Estadual Professora Ana Júlia de Carvalho Mousinho, aconteceram tendo como proposta o ensino de Iniciação à Programação com o Software Educacional Scratch, cujo intuito foi desmistificar o conceito popular de que o professor de Informática apenas dá aulas de Informática Básica, bem como a introdução ao Pensamento Computacional. Portanto, foram planejadas aulas teóricas e práticas para a oficina de Informática, trabalhando os conceitos dos elementos que compõem o Scratch, visto que neste software "a programação dispensa a digitação de código e se baseia em arrastar e soltar blocos de comandos" (BINI; KOSCIANSKI, 2009 , p. 6). Nesta seção, serão descritas as etapas realizadas para a concepção dos projetos criados pelos alunos participantes da oficina.

\subsection{Iniciação à programação com o uso da Computação Desplugada}

Nesta subseção será descrito o relato das aulas - metodologias utilizadas e os projetos desenvolvidos pelos alunos - da $2^{\mathrm{a}}$ edição da Oficina de Iniciação à Programação Utilizando o Scratch e a Computação Desplugada, no ano de 2016, da qual participaram 20 alunos do Ensino Médio (com idade entre quinze e vinte e um anos) do turno matutino, destes, 5 cursando o $1^{\circ}$ ano, 6 o $2^{\circ}$ ano, e 9 o $3^{\circ}$ ano, ministradas por duas bolsistas do PIBID subprojeto Informática, tendo na fase de concepção dos projetos o auxílio de mais um bolsista e um voluntário do $4^{\circ}$ período da Licenciatura em Informática do Instituto Federal de Educação, Ciência e Tecnologia do Rio Grande do Norte, campus Natal/Zona Norte.

Iniciou-se o módulo de Computação Desplugada, apresentando o conceito dos termos Computação Desplugada e Pensamento Computacional. Para a realização das atividades desse módulo propôs-se que a turma se dividisse em três grupos. Cada grupo deveria escolher um representante responsável por executar as instruções. Para explicar na prática como funciona a sequência de instruções que nos leva a resolução de um problema, foi proposta a atividade "Qual o objeto?", uma adaptação da atividade Descrevendo um objeto diário encontrada na página do Google for Education. Cada grupo recebeu um envelope contendo o nome de cinco objetos.

Os representantes de cada grupo descreveram os objetos, cada um para a sua equipe e os demais componentes tiveram um minuto para decifrar cada objeto descrito, escrevendo as instruções e desenhando o objeto. Foram utilizados o computador interativo, envelopes, cartões de papel ofício e canetas. Apenas um, dos três grupos, não 
conseguiu descobrir todos os objetos descritos pelo representante. Todos conseguiram compreender que para resolver um problema é necessário percorrer uma sequência de ações.

$\mathrm{Na} 2^{\mathrm{a}}$ aula realizou-se a atividade $O$ Labirinto criada com o objetivo de representar o funcionamento do computador no relacionamento solicitação do usuário $\mathrm{x}$ execução do sistema operacional. Para tanto, montou-se um labirinto dentro do Laboratório de Informática, delimitado com fita crepe, contendo obstáculos (cesto de lixo vazio, cadeiras, fita crepe, fios grossos de náilon) - segunda atividade de Computação Desplugada. Essa atividade foi realizada em duas etapas. Os alunos estavam fora da sala quando o labirinto foi montado. Um representante de cada grupo foi vendado para percorrer o labirinto, seguindo as instruções dos colegas. As regras foram: Não bater nos obstáculos ou na faixa de limite do labirinto, senão deveriam voltar ao início. Os participantes do grupo deveriam anotar as instruções dadas ao representante. Cada etapa foi cronometrada. Só foi permitida a presença na sala de um grupo por vez, os demais aguardaram fora do Laboratório. Utilizou-se fita crepe, cadeiras, cesto de lixo vazio e fios grossos de náilon. Os grupos executaram o percurso com tempos bem próximos, mas percebeu-se que utilizaram estratégias diferentes para conduzir o seu representante dentro do labirinto. Todos os alunos gostaram da atividade, e conseguiram compreender o funcionamento do computador.

$\mathrm{Na} 3^{\mathrm{a}}$ aula, foi realizada a atividade Memorização. Para representar o armazenamento e processamento de informações pelo computador, no momento de busca de arquivos solicitada pelo usuário, a atividade III consistiu em: Os representantes dos grupos observaram a sala, saíram e aguardaram enquanto a sala era reorganizada. Em seguida, um representante do grupo entrava no laboratório e deveria encontrar quais objetos haviam sido modificados. Tudo o que estava no laboratório podia ser modificado, até mesmo os alunos que lá permaneceram. O grupo não podia dar dicas sobre o objeto modificado. Foram realizadas 4 etapas ( 1 objeto, 2 objetos, 3 objeto, 4 objetos). Cada representante teve 1 minuto para executar cada etapa. Nesta atividade utilizou-se cadernos, bolsas, cadeiras, casacos, mochilas, entre outros objetos que estavam na sala. Os alunos conseguiram abstrair os conceitos de busca, informação, memória e processamento presentes na atividade.

$\mathrm{Na} 4^{\mathrm{a}}$ aula, a atividade consistiu em um mapa sequencial, composto por 8 pistas (questões) contendo problemas matemáticos e charadas a serem resolvidos, cada pista estava replicada em três cópias, tendo em vista que a turma foi dividida em 3 grupos (1 cópia para cada). As pistas foram escondidas em locais próximos ao Laboratório, na área interna da escola (quadra e pátio). Cada grupo precisou resolver o problema proposto em cada pista para passar à etapa seguinte. Foram utilizadas fichas impressas contendo os problemas a serem solucionados e fita crepe. Todos os grupos conseguiram resolver os problemas propostos, mas apenas um obteve um desempenho melhor considerando o tempo de conclusão da atividade.

$\mathrm{Na} 5^{\mathrm{a}}$ aula, apresentou-se o conteúdo a ser estudado durante o módulo Scratch e iniciou-se a primeira atividade. Devido os computadores estarem sem acesso à internet, foi necessário reformular a aula que teria como objetivo a resolução do desafio A Hora do Código do site code.org/learn que objetiva demonstrar que a programação pode ser ensinada de maneira lúdica, por meio da utilização de uma linguagem de blocos. Pensou-se então em executar as etapas do desafio Angry Birds da Hora do Código 
utilizando a Computação Desplugada.

Dessa vez, a turma foi separada em dois grupos, todos os componentes do grupo deveriam escrever o código para que o seu ator o executasse. Para simular as 20 etapas propostas no desafio, o caminho a ser percorrido foi demarcado utilizando fita crepe (Figura 1 (a) e (b)), enquanto para apresentar os blocos de comando, explicar as suas funções e mostrar as sugestões para a resolução das questões, utilizou-se apresentação de slides. Nesta aula apresentou-se os blocos de evento (quando executar), movimento (avance) e controle (repita (x) vezes). Foram utilizados o computador interativo, fita crepe, caneta e papel ofício. Os alunos conseguiram compreender a lógica utilizada para conseguir resolver as 8 primeiras questões do desafio.

$\mathrm{Na} 6^{\mathrm{a}}$ aula, a atividade realizada foi uma continuação da aula anterior. Sugeriu-se que os alunos utilizassem um novo bloco de repetição apresentado, o Repita Até, cujo objetivo é que o ator percorra todo o trajeto seguindo poucas instruções. Assim como na $5^{\mathrm{a}}$ aula, utilizou-se o computador interativo, fita crepe, caneta e papel ofício. Apesar de perceber-se algumas dificuldades em interpretar as situações propostas, os alunos tiveram um bom desempenho nas questões 9 a 12, após as seguidas explicações sobre o bloco de repetição Repita até, conseguiram compreender o objetivo da sua utilização. Na Figura 1, pode ser vista a dinâmica da aula.

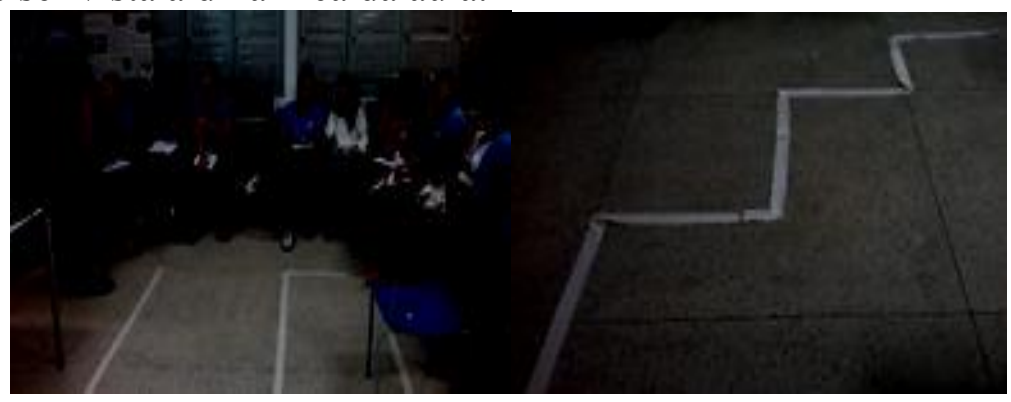

(a)

(b)

Figura 1. Alunos durante a atividade (a). Caminho demarcado com fita crepe (b).

$\mathrm{Na} 7^{\mathrm{a}}$ aula, deu-se continuidade às atividades de movimentação, agora com novo cenário, a turma foi dividida em duplas. Nesta aula, para alcançar os objetivos foram utilizados blocos de comandos mais complexos que o da movimentação básica. Os alunos escreveram os códigos no caderno, em seguida executaram no software Scratch o algoritmo, uma dupla por vez. Nesta atividade, foram utilizados 2 notebook's e o computador interativo. O uso de novos blocos de comando, semelhantes ao usado no módulo de Computação Desplugada, foi concluída sem maiores dificuldades.

$\mathrm{Na} 8^{\mathrm{a}}$ aula, foi apresentado um novo cenário às duplas, explorando também o uso dos blocos dos Sensores e de Controle, com a condição de que se o ator tocar na borda da pista deve voltar ao início. Os alunos escreveram os códigos com a resolução do problema no caderno e depois executaram no Scratch (no computador) o algoritmo escrito, uma dupla por vez. Nesta atividade, foram utilizados 2 notebook's e o computador interativo. Foi compreendido o uso dos blocos necessários para concluir a atividade.

As aulas de Iniciação à Programação com a metodologia Computação Desplugada, proporcionaram aos alunos momentos de descontração, colaboração, trabalho em equipe e principalmente de aprendizado. Em diálogo com a turma, o feedback sobre as atividades foi positivo, com pedidos de que houvesse continuidade. 
Alguns alunos destacaram dificuldades que tiveram durante a realização de algumas atividades, mas informaram que no decorrer das aulas foram superadas. Essa primeira etapa da Oficina foi realizada durante 8 aulas (1h por aula).

Com o objetivo de desenvolver habilidades de autonomia, criatividade e trabalho em grupo, a etapa seguinte da Oficina foi a formação de grupos para a produção de um projeto. Cada grupo precisava escolher um tema com fins educacionais. No entanto, os grupos eram responsáveis por escolher como os projetos seriam desenvolvidos no Scratch, por meio da criação de jogos, histórias ou mesmo animações.

Foi solicitado que cada grupo justificasse a escolha do tema do seu projeto. Foram formados cinco grupos (três grupos com quatro integrantes, um grupo com três integrantes e um com cinco integrantes). As etapas de desenvolvimento foram as seguintes: $1^{\text {a }}$ Pesquisa na internet do material para a elaboração do projeto; $2^{\mathrm{a}}$ Escolha de cenários e personagens; $3^{\mathrm{a}}$ Estruturar os códigos do projeto. $4^{\mathrm{a}}$ Acertos finais do projeto, revisão de código e funcionamento; $5^{\mathrm{a}}$ Apresentação. O desenvolvimento do projeto teve duração de dois meses (outubro e novembro de 2016, respectivamente), foi realizado no laboratório da escola, no horário da oficina.

\subsection{Descrição dos projetos desenvolvidos pelos alunos}

O grupo 1, com o projeto Pré-conceito (Figura 2), buscou abordar em forma de um jogo de perguntas e respostas situações de preconceito racial, de estereótipo, deficiência e xenofobia. Em cada questão, o jogador deve julgar a atitude correta a ser tomada pelo personagem diante da situação evidenciada. Ao final, é dado o feedback sobre o desempenho do jogador, e a pontuação final obtida.

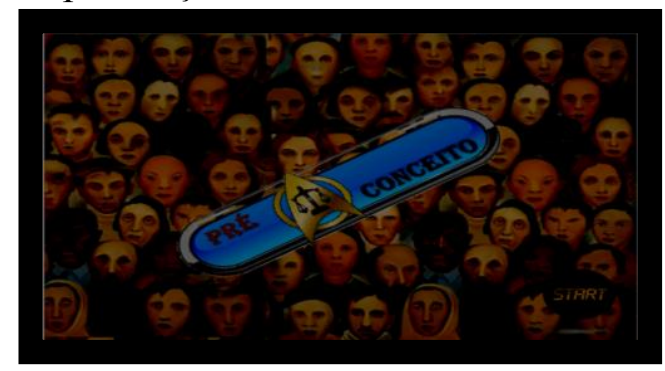

Figura 2. Projeto Pré-conceito.

O grupo 2, criou um jogo com cenários e personagens intergaláticos com o objetivo de revisar conceitos do Sistema Solar. O projeto Space Gari (Figura 3), conta a história do rei Ota que foi aprisionado por inimigos, para que o jogador ajude o personagem Kalígari a libertá-lo, deve responder corretamente às questões sobre os planetas do Sistema Solar. O Space Gari contém 3 fases, cada fase 5 questões, são disponibilizadas 3 tentativas em cada questão. Ao final da última fase existe 1 desafio, ao vencer o desafio, rei Ota é libertado.

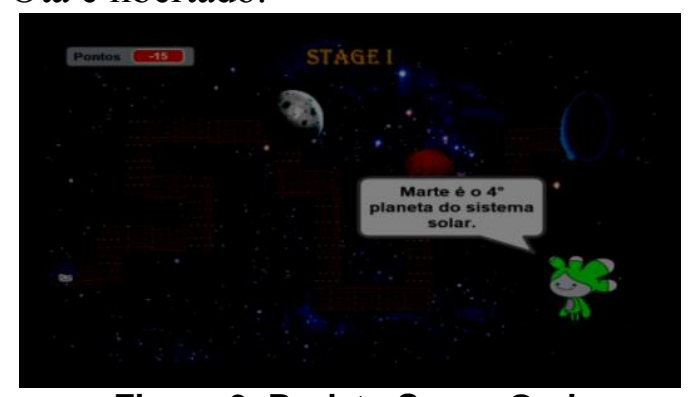

Figura 3. Projeto Space Gari. 
O grupo 3, com o projeto Quiz Biology (Figura 4), optou por criar um Quiz que contemplasse conteúdos estudados do $1^{\circ}$ ao $3^{\circ}$ ano do ensino médio, justificando que o projeto proporciona a partir da resolução das questões uma breve revisão de forma atrativa. Para cada série foram selecionados 3 temas, e para cada tema 5 questões. Os conteúdos são: $1^{\circ}$ ano - Sistema muscular, Órgãos dos sentidos e Introdução à biologia; $2^{\circ}$ ano - Desenvolvimento embrionário, Fotossíntese, Mitose e Meiose; e $3^{\circ}$ Teorias da evolução, Base sobre hereditariedade e Homosapiens. A cada resposta correta o jogador ganha 20 pontos, caso contrário, não ganha pontos, entretanto recebe a informação sobre a resposta correta.

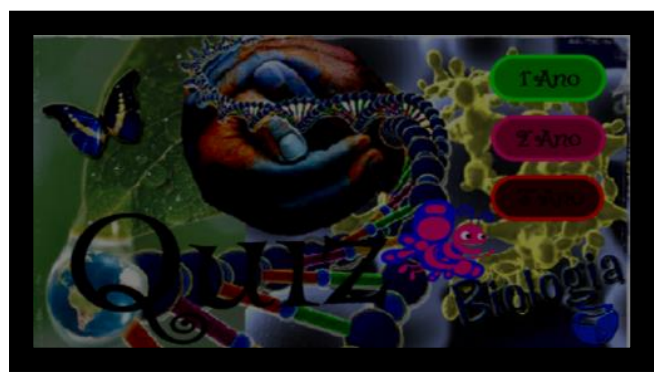

Figura 4. Projeto Quiz Biology.

O grupo 4, criou o projeto intitulado Quiz Testosterona (Figura 5), cujo nome foi escolhido por ser um grupo formado por rapazes, um Quiz contendo 4 questões para cada tema, cujos temas são Biologia, Matemática, Geografia e Conhecimentos Gerais. Para que o jogador selecione a quais questões quer responder, basta clicar no personagem correspondente ao tema. A cada questão respondida corretamente o jogador ganha 10 pontos. Ao final do Quiz é apresentado um Ranking contendo o nome dos jogadores, pontuação e a classificação.

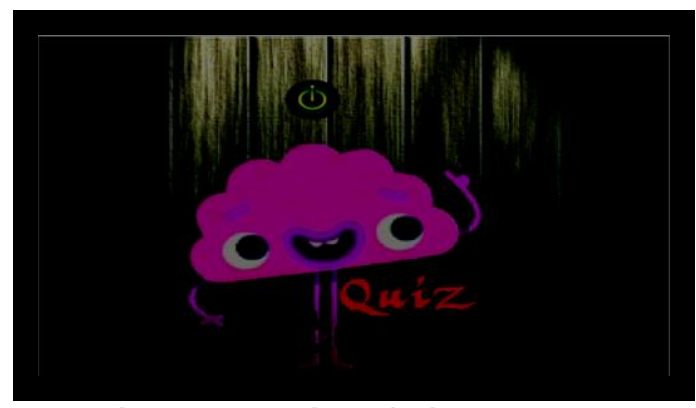

Figura 5. Projeto Quiz Testosterona.

O grupo 5, criou um jogo da Tabuada (Figura 6) com o objetivo de estimular a aprendizagem de cálculos básicos de maneira lúdica e desafiadora. Ao clicar na bandeira verde do Scratch, inicia-se o tempo de 60 segundos, durante esse tempo são informados 2 valores gerados aleatoriamente e a operação matemática. O jogador precisa responder o resultado do cálculo. A cada resposta correta o placar de pontos soma 1 e a cada erro subtrai 1 .

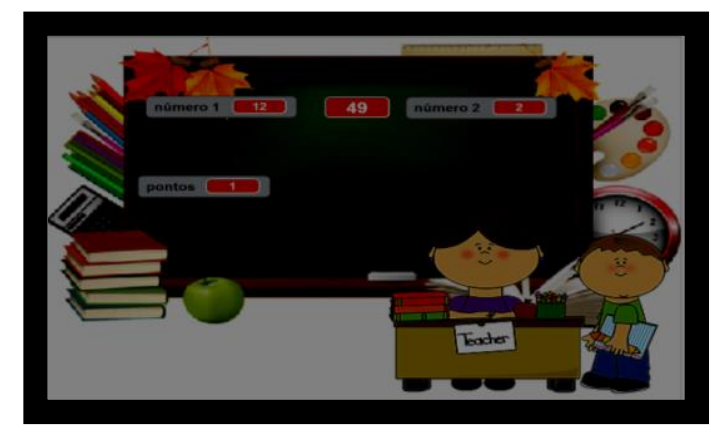

Figura 6. Projeto Tabuada. 
Na primeira semana de dezembro os grupos apresentaram os projetos mostrando o funcionamento, tendo a participação dos demais no momento da execução, falaram sobre as dificuldades no desenvolvimento e mostraram os blocos de comando utilizados. Na segunda semana de dezembro de 2016 a apresentação dos projetos foi realizada para a escola e comunidade. Todos os componentes dos grupos se envolveram na apresentação, explicando o funcionamento do projeto, objetivos, e convidando as pessoas para conhecerem o que eles haviam produzido. Foram elogiados, principalmente pela escolha dos temas. Pode-se ver a empolgação e participação dos alunos, o reconhecimento por parte da gestão da escola às atividades de Informática realizadas, pois percebe-se a relevância que o ensino da Informática trouxe aos envolvidos.

\subsubsection{Lições aprendidas}

As oficinas realizadas, em 2015 utilizando o Scratch, e em 2016 utilizando a Computação Desplugada, foram de suma importância tanto para mostrar que é possível desenvolver ações desse tipo na escola pública quanto para enfatizar as perspectivas de ensino da Informática por meio dos recursos computacionais. Os processos metodológicos utilizados na edição 2016 foram consequência da avaliação feita pelos alunos da edição 2015 (MARINHO et. al., 2017), e certamente corroborou com a saída da zona de conforto, para traçar novas estratégias.

Tendo em vista as metodologias distintas que foram utilizadas, torna-se necessário fazer uma breve consideração sobre as estratégias que demonstraram-se mais eficazes. No caso da turma de 2015, os alunos mostraram-se interessados, pois estavam conhecendo a ferramenta, dessa forma, tratavam cada bloco estudado com empolgação. Porém as dificuldades de compreensão da lógica para a implementação dos projetos, eram superiores comparadas à turma de 2016. Utilizando a Computação Desplugada, os alunos, sentiam-se desafiados a resolver os problemas propostos, e demonstravam melhor compreensão da lógica de programação na execução das atividades.

\section{Considerações finais}

A avaliação feita por parte dos alunos, por meio do questionário aplicado ao final da Oficina, mostrou que os objetivos da proposta foram alcançados, por mais que tenham havido algumas dificuldades na resolução dos desafios que foram propostos durante $o$ percurso. A análise das respostas foi fundamental para o planejamento da segunda edição da Oficina. Em 2016, no final de mais uma Oficina, os objetivos foram concretizados novamente. Os cinco grupos apresentaram os seus projetos na Feira de Arte e Cultura (FESTAC) - O evento acontece anualmente e tem por objetivo envolver a escola em situações do cotidiano através de projetos que foram desenvolvidos durante o ano letivo. Dessa vez os projetos abordaram temáticas relacionadas às disciplinas de Biologia, Geografia, Matemática e História. Sendo assim, diante do relato apresentado neste trabalho pode-se inferir que existe a possibilidade de implementação de atividades de Informática/computação nas escolas públicas, mesmo diante dos desafios constantes.

A experiência relatada corrobora com a ideia de que a computação dispõe de diversos recursos, os quais podem trazer contribuições significativas ao processo de ensino e aprendizagem. Este trabalho visa mostrar que mesmo com a utilização tímida de um software de iniciação a programação, é possível a operacionalização de um trabalho didático-pedagógico significativo. Considerando a importância dos estudantes 
desenvolverem habilidades de resolução de problemas, e tendo em vista que é possível mobilizar essas habilidades por meio de atividades que envolvam situações do dia a dia, ou de conteúdos relacionados às disciplinas curriculares. Entende-se que é relevante tornar a aprendizagem mais significativa durante o processo de ensino.

A partir da análise dos resultados alcançados nas duas oficinas, pretende-se ampliar as ações de Iniciação à Programação na Educação Básica. Visto que, assim como as experiências realizadas no Ensino Médio tiveram sucesso, busca-se implementar tais ações também no Ensino Fundamental. De tal forma, possibilitar que mais estudantes tenham acesso aos conhecimentos operacionalizados em atividades que envolvam recursos computacionais.

\section{Referências}

Bini, E. M., Koscianski, A. (2009) "O ensino de programação de computadores em um ambiente criativo e motivador". In: Encontro Nacional de Pesquisa em Educação em Ciências. Florianópolis/SC.

Cavalcante, A. F. et al. (2016) "Um Estudo de Caso Sobre Competências do Pensamento Computacional Estimuladas na Programação em Blocos no Code.Org”. In: Anais dos Workshops do V Congresso Brasileiro de Informática na Educação. Uberlândia/MG.

Code Studio. (2017) “About Code Studio", http://code-studio.com/about-us/, Novembro.

Gomes, T. C. S; Tedesco, P. C. DE A. R; Melo J. C. B. (2016) "Jogos no Design de Experiências de Aprendizagem de Programação Engajadoras". In: V Congresso Brasileiro de Informática na Educação (CBIE 2016). V Jornada de Atualização em Informática na Educação (JAIE 2016). Uberlândia/MG.

Libâneo, J. C. (2000) "As novas tecnologias da comunicação e informação, a escola e os professores". In: Adeus professor, adeus professora? Novas exigências educacionais e profissão docente. Cortês: São Paulo.

Marinho, A. R. da S. et. al. (2017) "O uso do Scratch na Educação Básica: Um relato de experiência vivenciada no PIBID. In: XXIII Workshop de Informática na Escola, Recife/PE.

Scratch. (2015) “About Scratch", http://scratch.mit.edu/about, Janeiro.

Silva, F. B.; Romani, R., Baranauskas, M. C. C. (2008) "Soo Brasileiro: Aprendizagem E Diversão". No Xo. Revista Brasileira de Informática na Educação, p.29-41.

Tripp. David. (2005) "Pesquisa-ação: uma introdução metodológica". In: Educação e Pesquisa, São Paulo, v. 31, n. 3, p. 443-466, set./dez.

Vieira, A.; Passos, O.; Barreto, R. (2013) "Um relato de experiência do uso da técnica computação desplugada". In: SBC 2013, pages 670-679.

Vygotsky, L. S. (1987) “Thinking and speech" (N. Minick, Trans.). In R. W. Rieber \& A. S. Carton (Eds.), The collected works of L. S. Vygotsky: Vol. 1. Problems of general psychology (pp. 39-285).

Wing, J. M. (2006) "Computional Thinking”. In: Communications of the ACM. March 2006/Vol. 49, No.3. 